\title{
Nova Espécie do Complexo oliveirai (Nova Denominação para o Complexo matogrossensis) (Hemiptera, Reduviidae, Triatominae) do Estado do Rio Grande do Sul, Brasil
}

\author{
Rodolfo U Carcavallo/ ${ }^{+}$, José Jurberg, Herman Lent* , Cleber Galvão, \\ Mário Steindel**, Carlos José Carvalho Pinto**
}

\begin{abstract}
Laboratório Nacional e Internacional de Referência em Taxonomia de Triatomíneos, Departamento de
Entomologia, Instituto Oswaldo Cruz, Av. Brasil 4365, 21045-900 Rio de Janeiro, RJ, Brasil *Centro de Ciências Biológicas, Universidade Santa Úrsula, Rio de Janeiro, RJ, Brasil **Departamento de Microbiologia e Parasitologia, Centro de Ciências Biológicas, Universidade Federal de Santa Catarina, Florianópolis, SC, Brasil

A New Species of the oliveirai Complex (New Designation for matogrossensis Complex) from the State of Rio Grande do Sul, Brazil - The authors describe a new species of Triatominae (Hemiptera, Reduviidae) from the State of Rio Grande do Sul, Brazil. The study was made with specimens captured in basaltic formations, at an average altitude of 750 m.o.s.l. The new species is included in the oliveirai complex together with other four species $\mathrm{T}$. williami, T. matogrossensis, T. guazu and T. jurbergi). The new species was compared with the most similar one, T. oliveirai, from which the main differences are on the proportions of head, ante and postocular regions, the general color pattern and the male genitalia, specially on the median process of the pygophore, the support of phallosome, the vesica and the process of the endosome.
\end{abstract}

Key words: Triatoma klugi sp. n. - Triatoma oliveirai - oliveirai complex - Triatominae - Chagas disease - Brazil

Na subfamília Triatominae existem atualmente 17 gêneros com 130 espécies (Carcavallo et al. 1999, Mejia et al. 1999); os gêneros Rhodnius, Panstrongylus e Triatoma possuem numerosas espécies que podem ser reagrupadas em "complexos específicos" de acordo com as semelhanças entre si. Este agrupamento é prático apesar de não ser uma categoria incluída no Código Internacional de Nomenclatura Zoológica. Os autores estudam atualmente as possibilidades da categoria subgenérica no futuro para estes "complexos".

O conceito de "complexo específico" para Triatominae foi desenvolvido por Usinger et al. (1966). Posteriormente, Lent e Wygodzinsky (1979) reconheceram a existência de vários complexos no gênero Triatoma sendo os mais importantes aqueles vinculados com $T$. infestans, $T$. phyllosoma, $T$. sordida e $T$. protracta. O "complexo específico" é um conjunto de espécies e ou subespécies com semelhanças morfológicas, pos-

Com auxílio do CNPq e Convênio FNS/Fiocruz no $123 / 97$ +Autor de contato. Fax: +55-21-290.9339. E-mail: carcaval@gene.dbbm.fiocruz.br Recebido em 26 de abril de 2000 Aceito em 9 de agosto de 2000 síveis hibridizações e proximidade molecular nos estudos bioquímicos, como por exemplo, nas análises iso-enzimáticas e através de outras abordagens. Carcavallo et al. (1999) reconheceram vários complexos nos três gêneros acima referidos e mostraram em mapas as possíveis origens e distribuição dos complexos T. infestans com origem na Bolívia se espraiando pela Bolívia, pelo Paraguai e pelo norte da Argentina; T. sordida, com uma distribuição do centro-norte do Brasil incluindo a Argentina, o Paraguai e o leste da Bolívia; $T$. dimidiata, com ampla distribuição geográfica desde o centro do México até a Colômbia e atingindo o Peru, e T. protracta com o mapa de dispersão elaborado por Ryckman (1962).

No presente trabalho, descrevemos e relacionamos esta nova espécie a um grupo de espécies próximas, difíceis de separar pelas características ninfais, e que mostraram algum nível de hibridização quando experimentalmente se procurou formar casais interespecíficos. Neste grupo, previamente denominado "complexo T. matogrossensis" (Carcavallo et al. 1999), estão incluídas T. matogrossensis Leite \& Barbosa (1953); T. williami Galvão, Souza \& Lima, 1965; T. guazu Lent \& Wygodzinsky, 1979, T. jurbergi Carcavallo, Galvão \& Lent, 1998 e agora T. klugi sp. n. e T. oliveirai, espécie que atualmente dá nome ao complexo por ter sido a primeira a ser descrita neste grupo. 
T. oliveirai e T. klugi sp. n. são as únicas espécies do grupo que até o presente não foram encontradas no estado do Mato Grosso, Brasil. Foi feita uma comparação com $T$. oliveirai, espécie morfologicamente mais próxima, através do estudo morfológico comparativo das estruturas fálicas, das relações da cabeça e dos segmentos do rostro (Tabela).

Ao longo dos últimos três decênios, a análise comparativa das estruturas fálicas tem se mostrado um elemento importante para caracterizar e separar as espécies. Desde 1965, quando Lent e Jurberg identificaram uma espécie nova, Psammolestes tertius, tornou-se indispensável usar esta abordagem não só para situar as espécies através da comparação da forma entre as estruturas, como para situar os gêneros através da ausência ou presença das estruturas e criar condições para uma abordagem filogenética (Jurberg 1995). Assim, além da descrição de novas espécies, foi revalidado o gênero Mepraia Mazza, Gajardo \& Jorg, 1940, e descritos os gêneros Hermanlentia Jurberg \& Galvão, 1997 e Torrealbaia Carcavallo, Jurberg \& Lent, 1998 e descoberto o possível "elo perdido" ao encontrar no gênero Rhodnius duas espécies, $R$. pictipes e $R$. stali, com uma estrutura comum aos outros gêneros, o suporte do falosoma que é inexistente em todas as outras espécies do gênero Rhodnius (Lent et al. 1993, 1994, Jurberg e Galvão 1997, Jurberg et al. 1998).

Triatomíneos coletados em frestas de rochas no morro Malakov na localidade de Linha Brasil, município de Nova Petrópolis, estado do Rio Grande do Sul, foram recebidos para identificação. Após análise morfológica concluiu-se que se tratava de novo táxon denominado Triatoma klugi sp. n. (Fig. 1).

O morro Malakov faz parte da formação Serra Geral; é constituído por rochas basálticas de origem vulcânica e o local da captura situa-se entre

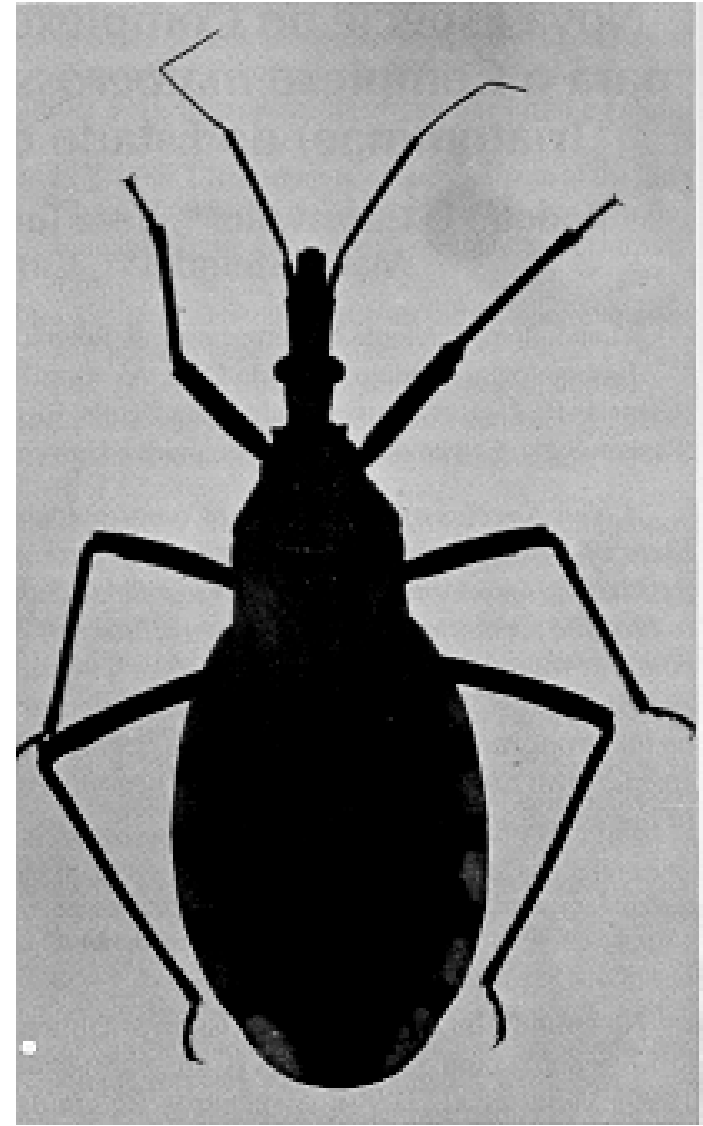

Fig. 1: Triatoma klugi sp.n., macho

700 e $800 \mathrm{~m}$ de altitude (29022'55"S e 51 $\left.{ }^{\circ} 11^{\prime} 29^{\prime \prime} \mathrm{O}\right)$ (Fig. 2). O município de Nova Petrópolis está localizado na região serrana do nordeste do Rio Grande do Sul. A altitude média da região é de $604 \mathrm{me}$ o município dista $100 \mathrm{~km}$ da capital, Porto Alegre (Fig. 3). As variações de altitude na região deter-

\section{TABELA}

Caracteres morfológicos diferenciais entre Triatoma klugi sp.n. e Triatoma oliveirai (Neiva, Pinto \& Lent, 1939)

\begin{tabular}{lll}
\hline Caracteres & Triatoma klugi sp.n. & Triatoma oliveirai \\
\hline Cabeça & Maior (Figs. 21, 23) & Menor (Figs. 22, 24) \\
Região ante-ocular & 1 & 1 \\
Região ocular & 0.28 & 0.22 \\
Região pós-ocular & 0.37 & 0.34 \\
Largura interocular & 1 & 1 \\
Largura da cabeça & 2.31 & 2.23 \\
Processo mediano do pigóforo & Curto (Fig. 5) & Longo, base circular projetada \\
Suporte do falosoma & Maior, ápice em forma de pinça (Fig. 8) & (Fig. 13) \\
& & Menor, ápice em forma de espátula \\
Vesica & Ápice liso, menor (Fig. 9) & Ápice com corcova, maior (Fig. 18) \\
Processo do endosoma & Bordo superior liso (Fig. 10) & Bordo superior ondulado (Fig. 17) \\
Abdômen & Maior (Fig. 19) & Menor (Fig. 20) \\
\hline
\end{tabular}


minam diferenças térmicas consideráveis no município. Nos vales o verão é quente e úmido e a temperatura pode chegar a $30^{\circ} \mathrm{C}$; na serra o frio é intenso e a temperatura pode ficar abaixo de $0^{\circ} \mathrm{C}$, no inverno, com ocorrência de geadas e até neve.

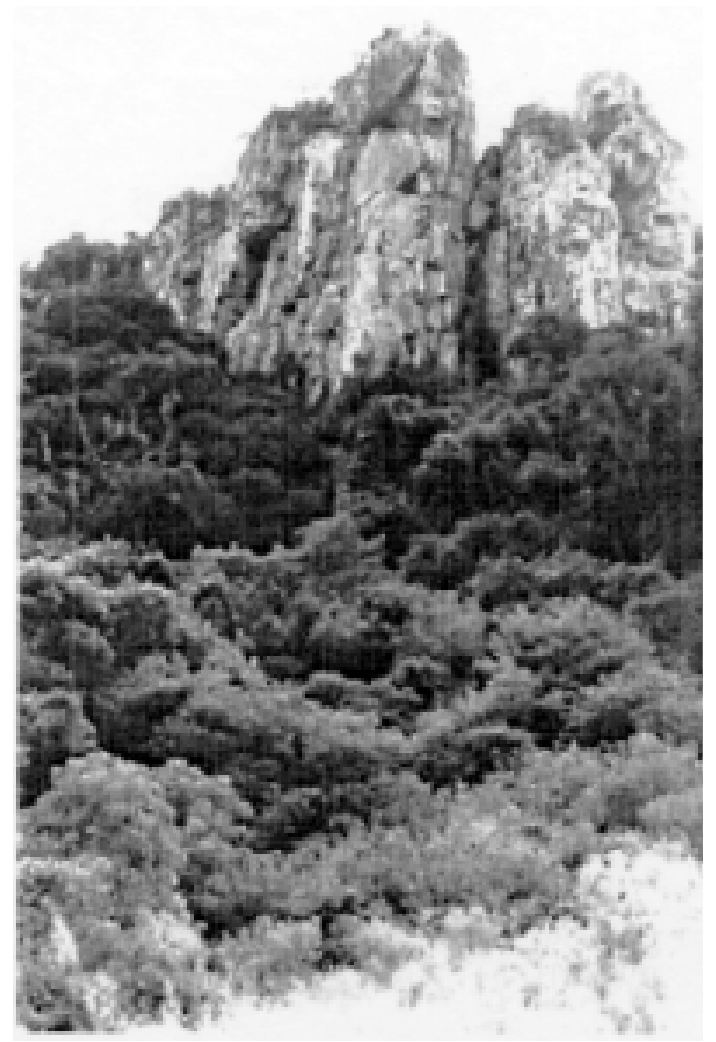

Fig. 2: vista geral do morro Malakov, Nova Petrópolis, RS, Brasil

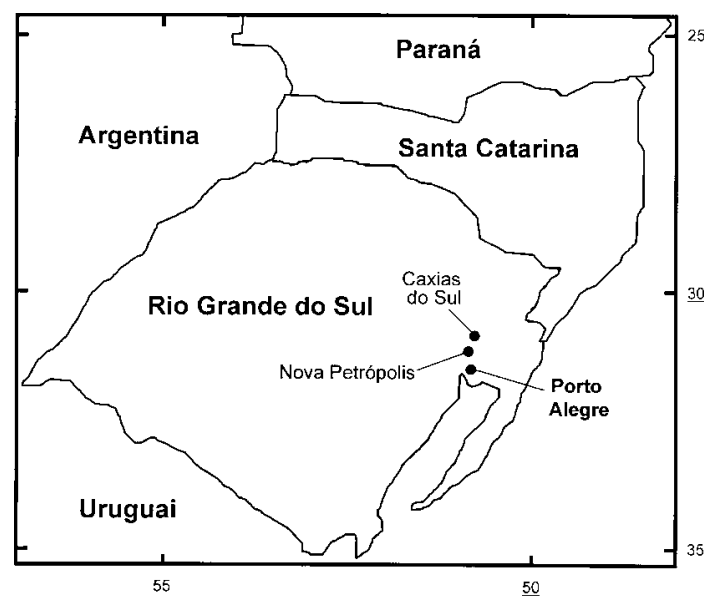

Fig. 3: mapa de parte da Região Sul do Brasil, assinalando o município de Nova Petrópolis.

\section{DESCRIÇÃO}

Triatoma klugi sp. n. Carcavallo, Jurberg, Lent \& Galvão.

Comprimento total dos machos: $24-25 \mathrm{~mm}$, largura do pronoto $4 \mathrm{~mm}$, largura do abdômen 8 $\mathrm{mm}$; fêmeas: comprimento total $25-27 \mathrm{~mm}$, largura do pronoto $4 \mathrm{~mm}$, largura do abdômen $10 \mathrm{~mm}$ (Fig. 1).

Insetos de cor geral preta, tendo manchas amarelas centrais em cada segmento do conexivo, parte externa do clavo e a base do cório, são escuras as partes distais do cório e acinzentadas as membranas. Fêmeas com caracteres e proporções semelhantes aos machos, as asas só atingem a região basal do VII urotergito, ficando afastado do bordo posterior.

Macho: cabeça preta, sem manchas, delicadamente granulosa, três vezes mais longa do que larga, como também mais longa que o pronoto (Fig.1).

Região ante-ocular 3,5-4 vezes mais longa que a pós-ocular não convergindo posteriormente com os bordos delicadamente arredondados. Região interocular (sinlipsis) 1,5 vezes maior que um diâmetro ocular em vista dorsal. Olhos globosos e pequenos, ocelos bem visíveis, bordo inter-ocelar fracamente marcado. Clípeo alongado, alargado na região posterior. Genas rugosas e granulosas ultrapassando o ápice do clípeo em forma aguçada. Jugas rugosas e granulosas formando ângulo apicalmente. Olhos em vista lateral atingem o bordo inferior, mas não o superior.

Tubérculos anteníferos implantados na parte média da região anteocular. Primeiro segmento antenal não atinge a extremidade do clípeo (proporções 1:3,5:2,4:?).

Rostro de coloração preta, granuloso, com o terceiro segmento de cor marrom; o primeiro segmento não atinge o ápice do tubérculo antenífero, o segundo ultrapassa o bordo posterior do olho em vista lateral, o terceiro com pilosidade densa e longa (proporções 1:2,5:1,2) (Figs. 5, 21, 23).

Colar preto, delicadamente granuloso, pronoto preto, brilhante, bastante rugoso, lobo anterior com tubérculos discais vestigiais, sem tubérculos laterais, ângulos ântero-laterais divergentes, cônicos e aguçados. Lobo posterior bastante rugoso com as carenas sub-medianas, o sulco médio e os ângulos humerais bem nítidos.

Escutelo muito rugoso com a depressão central muito profunda e o processo do escutelo cônico, pequeno e voltado para cima.

Hemiélitros não atingem o bordo posterior do abdômen, apenas a metade do VII urotergito, clavo parcialmente escuro na margem externa com exceção do 1/4 basal, cório amarelado com nervuras pretas e áreas mais escuras entre as nervuras, membrana cinza com as nervuras mais escuras. 

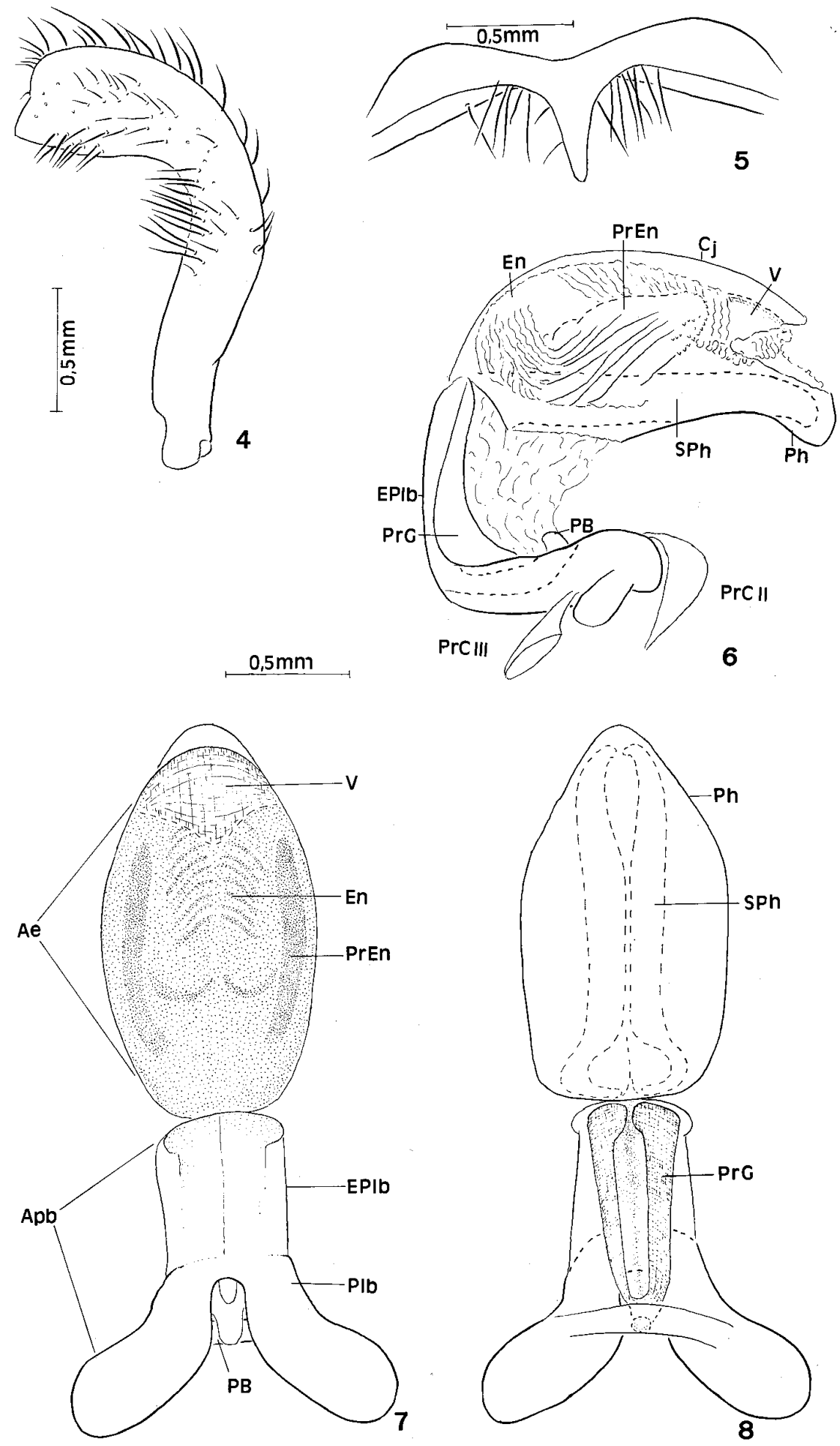

Triatoma klugi sp.n., genitália do macho. Fig. 4: parâmero, vista dorsal. Fig. 5: processo mediano do pigóforo. Fig. 6: falo em repouso, vista lateral. Fig. 7: falo distendido, vista dorsal. Fig. 8: falo distendido, vista ventral. (Ae: edeago, Apb: aparelho articular; En: endosoma; Eplb: extensão mediana da placa basal; Cj: conjuntiva; En: endosoma; EPlb: extensão mediana da placa basal; PB: ponte basal; Ph: falosoma; PrEn: processo do endosoma; PrG: processo do gonoporo; PrCII e III: processo capitato II e III; SPh: suporte do falosoma; V: vesica) 

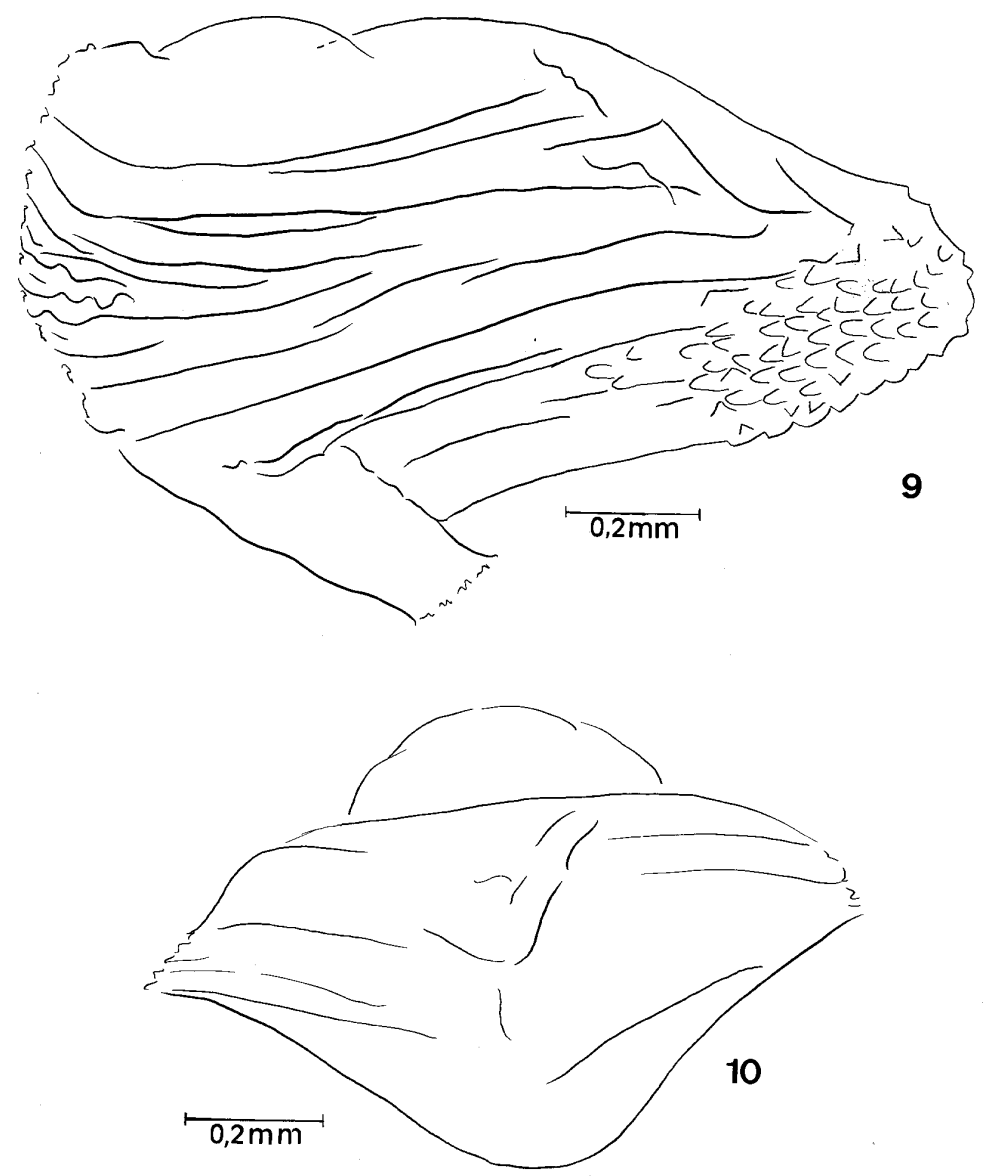

Triatoma klugi sp.n., genitália do macho. Fig. 9: processo do endosoma. Fig. 10: vesica
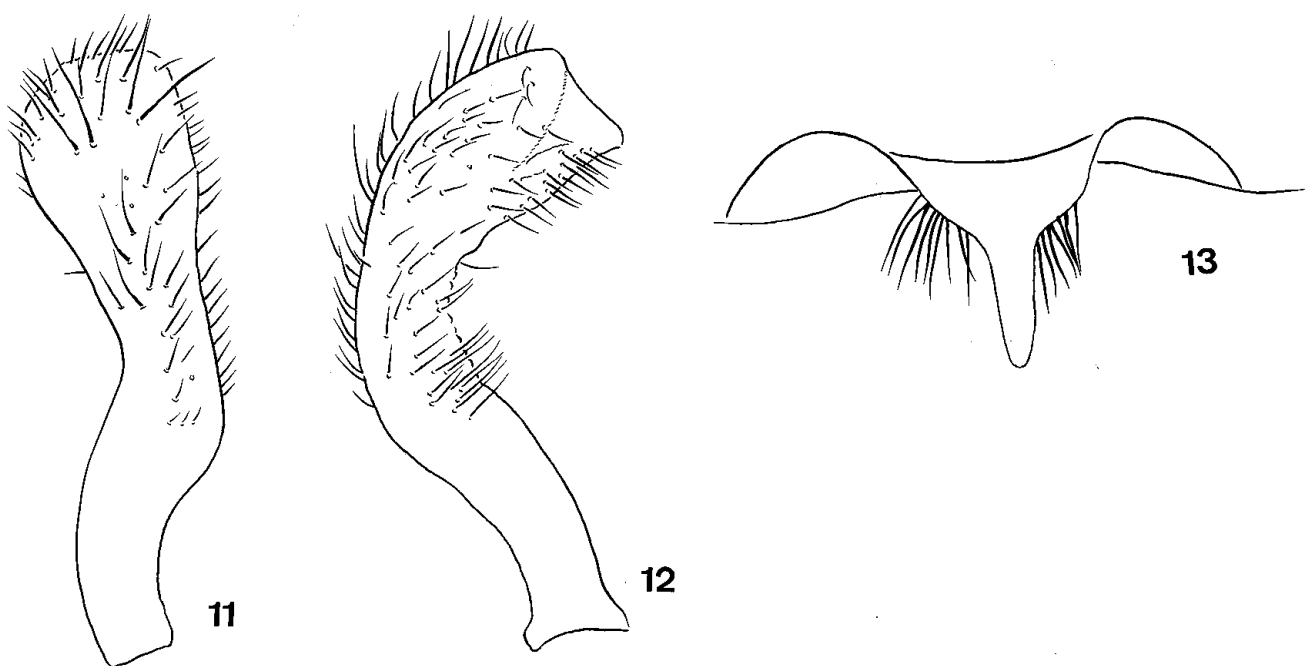

Triatoma oliveirai (Neiva, Pinto \& Lent, 1939) genitália do macho. Fig. 11: parâmero, vista lateral. Fig. 12: parâmero, vista ventral. Fig. 13: processo mediano do pigóforo 

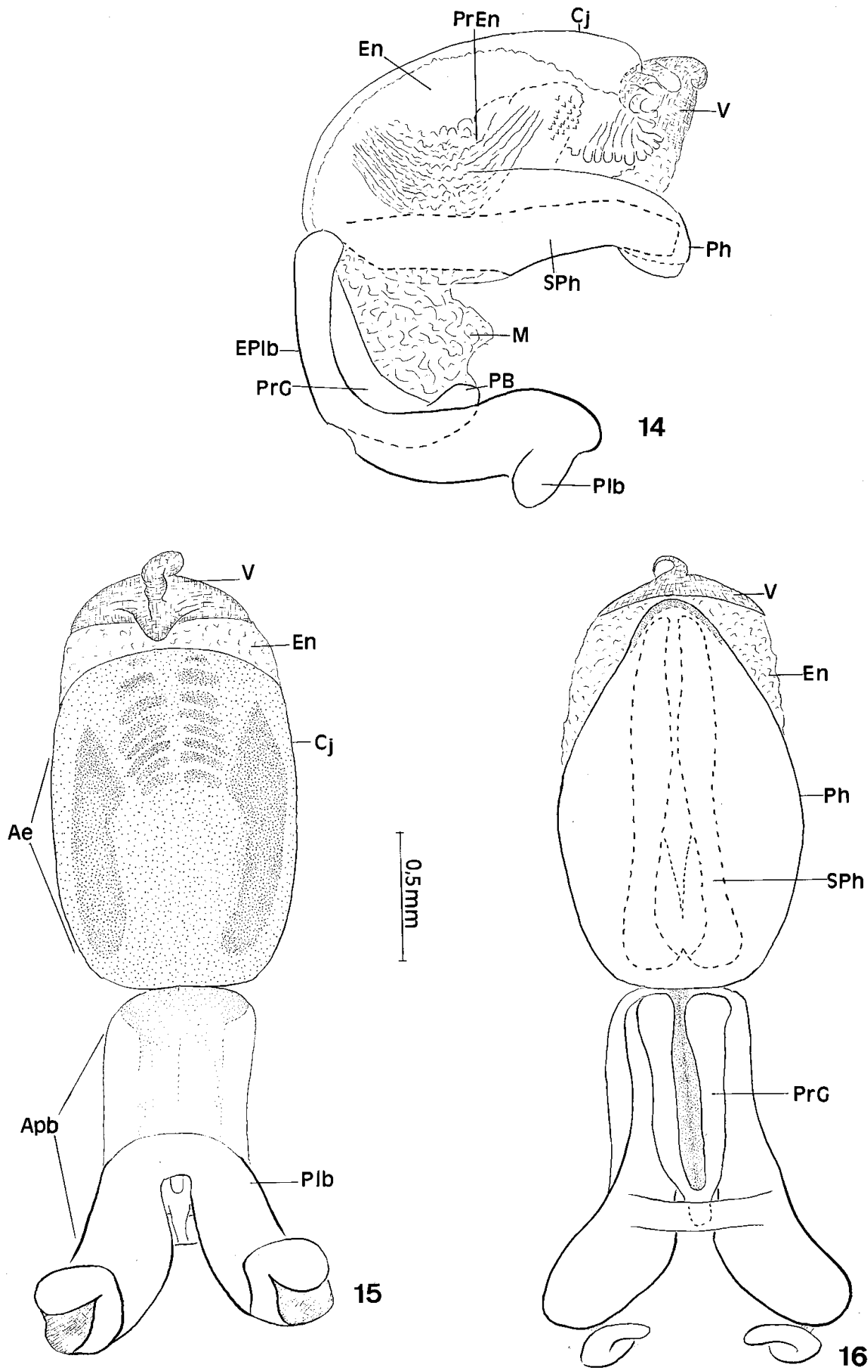

Triatoma oliveirai (Neiva, Pinto \& Lent, 1939) genitália do macho. Fig. 14: falo em repouso, vista lateral. Fig. 15: falo distendido, vista dorsal. Fig. 16: falo distendido, vista ventral 
Patas uniformemente pretas, longas e delgadas, fêmur anterior oito vezes mais longo do que largo, fêmures anteriores e médios com $1+1$ tubérculos pequenos na união do $1 / 4$ apical com os $3 / 4$ proximais. Fossetas esponjosas presentes nas tíbias anteriores e médias.

Abdômen ventralmente convexo, brilhante preto, com estrias transversais muito delicadas e pilosidade dispersa com cerdas curtas. Espiráculos no limite da sutura do conexivo. Conexivo com mácula amarela no centro de cada segmento (Fig. 19).

Genitália do macho: o falo é uma estrutura complexa composta de duas partes: o aparelho articular e o edeago, ambas com o mesmo tamanho e $1+1$ parâmeros que funcionam como órgãos acessórios à cópula. Em repouso, o aparelho articular fica fletido sobre o edeago dentro do $9^{\underline{0}}$ segmento abdominal, também denominado pigóforo, de onde se projetam os parâmeros ladeando a abertura genital que possui no seu bordo inferior uma estrutura bastante quitinizada, denominada processo mediano do pigóforo (Figs. 4 a 10).

O aparelho articular é uma estrutura com o formato da letra $\mathrm{Y}$ invertida, sendo que os braços divergentes se constituem na placa basal e o braço ímpar na extensão mediana da placa basal; associados a esta estrutura encontramos na face interna o processo do gonoporo, um tubo oco, cuja base maciça esta soldada à ponte basal que liga os dois braços divergentes. A placa basal articula o movimento do falo para se exteriorizar através dos processos capitato 1,2 e 3 , que se prendem na parede interna do 9o segmento e do processo mediano do pigóforo e aos parâmeros (Figs. 6 a 8).

O edeago é um corpo ovóide, complexo, constituído de seis elementos. Externamente, uma membrana denominada conjuntiva envolve toda a área superior do edeago; a área inferior é limitada por uma placa quitinizada denominada falosoma. Internamente estão situados o endosoma, um corpo membranoso que se exterioriza no ato da cópula e ao qual estão soldados duas estruturas, $1+1$ processos do endosoma, vésica que se localiza no ápice do edeago de formato triangular e fracamente quitinizada e o suporte do falosoma estrutura cilíndrica, base dilatada formada por uma ou duas hastes justapostas cujos bordos internos se afastam levemente no $1 / 3$ apical e se aproximam no ápice (Figs. 6 a 9).

Parâmeros cilíndricos, robustos, dobrados para dentro na região mediana, tendo uma projeção triangular no ápice, bordo interno e externo com pêlos longos, superfície externa com pêlos curtos, todos na metade apical (Fig. 4).

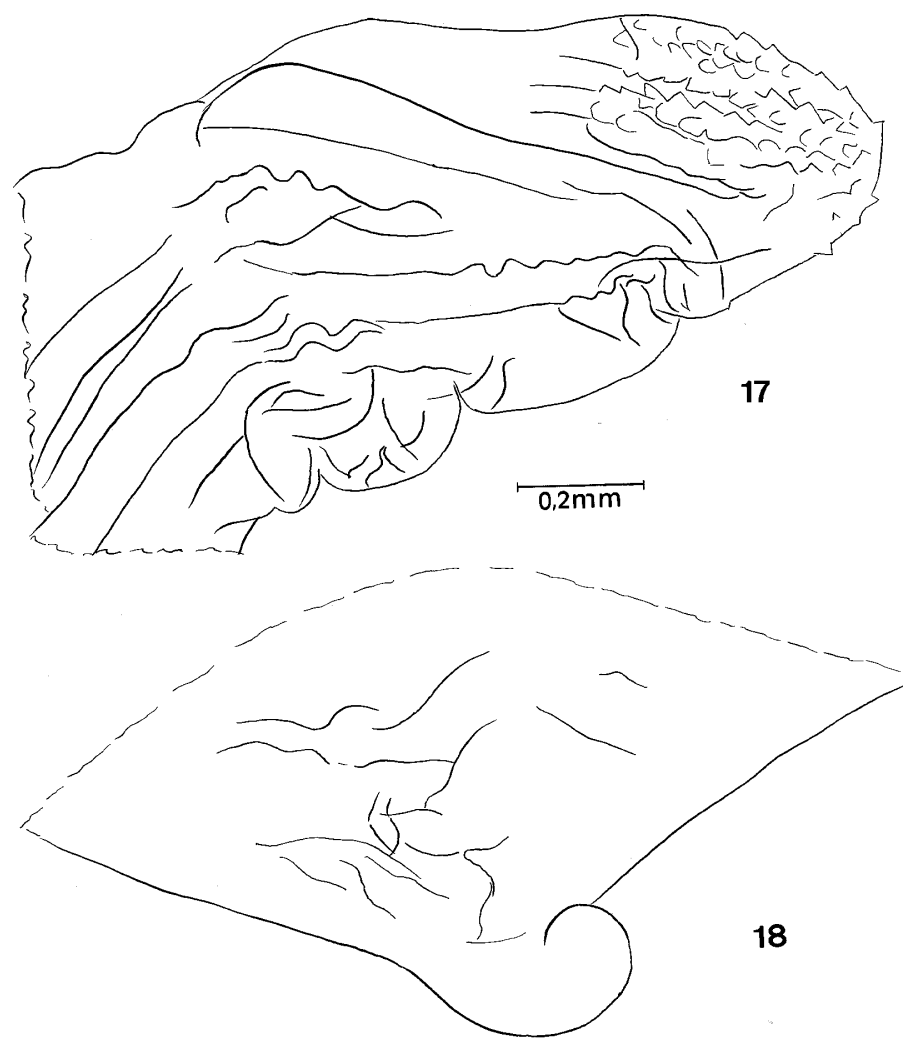

Triatoma oliveirai (Neiva, Pinto \& Lent, 1939) genitália do macho. Fig. 17: processo do endosoma; Fig. 18: vesica 

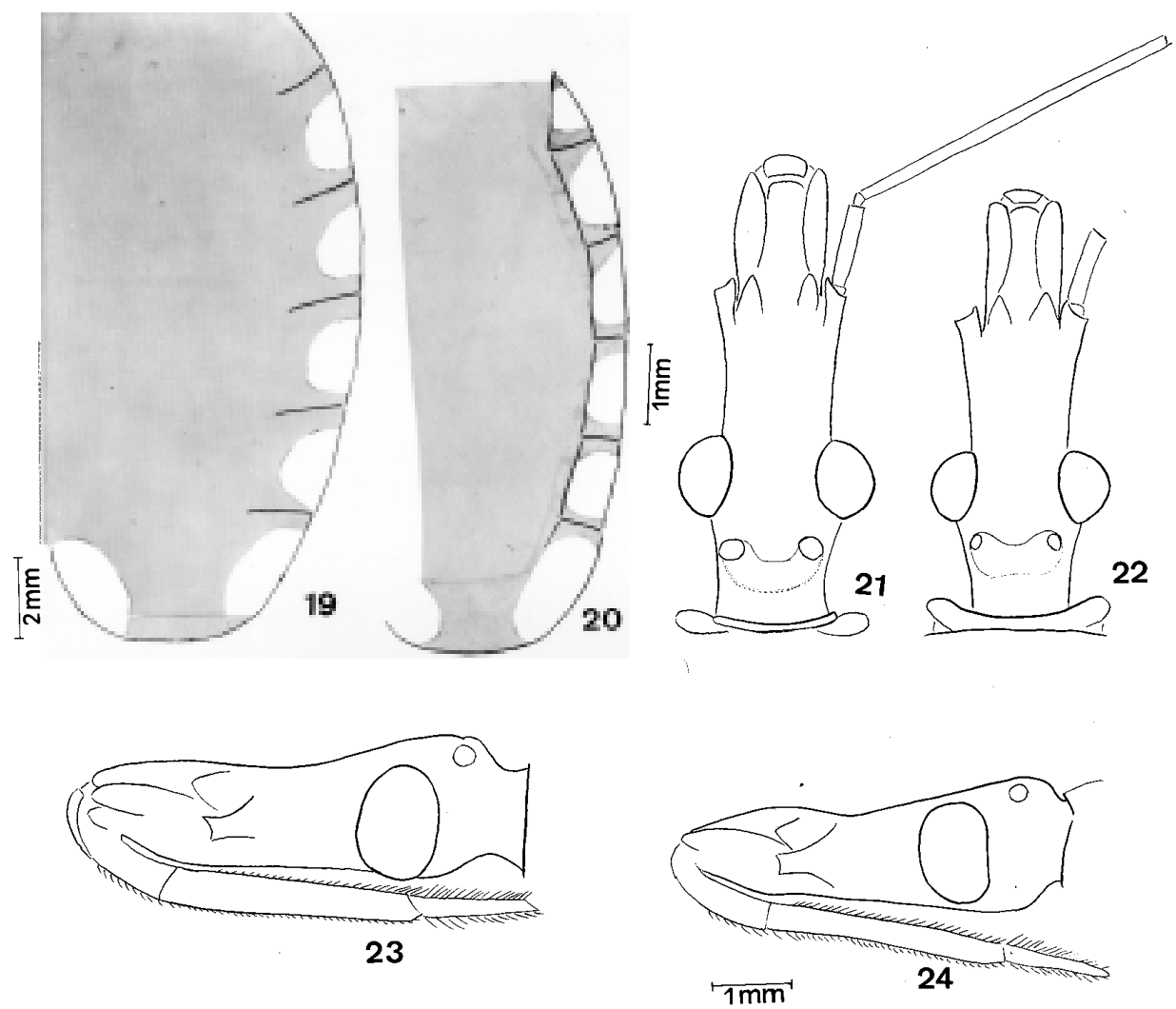

Fig. 19: Triatoma klugi sp.n., abdômen, vista dorsal. Fig. 20: Triatoma oliveirai (Neiva, Pinto \& Lent, 1939) abdômen, vista dorsal. Fig. 21: Triatoma klugi sp.n., cabeça, vista dorsal. Fig. 22: Triatoma oliveirai (Neiva, Pinto \& Lent, 1939), cabeça, vista dorsal. Fig. 23: Triatoma klugi sp.n., cabeça, vista lateral. Fig. 24: Triatoma oliveirai (Neiva, Pinto \& Lent, 1939), cabeça, vista lateral

Processo mediano do pigóforo triangular, curto com numerosas cerdas na base (Fig. 5).

Etimologia: o nome específico é uma homenagem a Johann Christoph Fiedrich Klug (17751856) que nasceu em Berlin em 5 de maio de 1775 , era entomólogo e descreveu numerosas espécies de insetos, inclusive do Brasil. O que se conhece hoje como Triatoma infestans (Klug, 1834) foi descrito à página 412 do livro de Franz Julius Ferdinand Meyen como Reduvius infestans. Na realidade deveria ser referido como Triatoma infestans (Klug in Meyen, 1834). Estas informações sobre Klug foram cedidas por Hitoshi Nomura, historiador que vem se dedicando à biografia de zoólogos do século XVI até o século XIX.

Material examinado: holótipo macho no 5606, alótipo fêmea $\mathrm{n}$ ㅇ 5607, três parátipos machos $\mathrm{n}$ os $5608,5609,5610$ e um parátipo fêmea no -5611 de Nova Petrópolis, estado do Rio Grande do Sul, Brasil, depositados na Coleção Rodolfo Carcavallo. Cinco parátipos machos nos 2925, 2926, 2927, 2928, 2929 e dois parátipos fêmeas no 2930,2931 da mesma procedência depositados na Coleção Herman Lent. As duas coleções fazem parte do acervo da Coleção Entomológica do Instituto Oswaldo Cruz, e estão sob a responsabilidade e guarda do Laboratório Nacional e Internacional de Referência em Taxonomia de Triatomíneos, Departamento de Entomologia do Instituto Oswaldo Cruz.

Diagnose: Triatoma klugi sp.n. pertence a um complexo de espécies formado por $T$. oliveirai, $T$. williami, espécies que juntamente com $T$. matogrossensis, T. guazu e T. jurbergi formam um grupo bastante uniforme de espécies semelhantes. T. oliveirai e $T$. guazu, as espécies mais próximas, se distinguem com relativa facilidade, pois $T$. oliveirai tem cores e manchas diferentes, especialmente nas asas, que são amarelas, claras e muito curtas em T. oliveirai e escuras com membranas cinzas na nova espécie. T. guazu é uma espécie maior (26 $\mathrm{mm}$ os machos e $30 \mathrm{~mm}$ as fêmeas), tamanho que T. klugi sp. n. não alcança; as genitálias dos machos e das fêmeas são também muito diferentes. 


\section{REFERÊNCIAS}

Carcavallo RU, Jurberg J, Lent H 1999. Phylogeny of the Triatominae. A - General approach. In RU Carcavallo, I Galíndez-Girón, J Jurberg, H Lent (orgs.), Atlas of Chagas' Disease Vectors in the Americas, Vol. III, Ed. Fiocruz, Rio de Janeiro, p. 925-969.

Jurberg J 1995. Uma abordagem filogenética entre os triatomíneos baseada nas estruturas fálicas (Hemiptera, Reduviidae). Mem Inst Oswaldo Cruz 90: 59.

Jurberg J, Galvão C 1997. Hermanlentia n. gen. da tribo Triatomini, com um rol de espécies de Triatominae (Hemiptera, Reduviidae). Mem Inst Oswaldo Cruz 92: 181-185.

Jurberg J, Lent H, Galvão C 1998. Male genitalia and its importance in taxonomy. In RU Carcavallo, I Galíndez-Girón, J Jurberg, H Lent (orgs.), Atlas of Chagas' Disease Vectors in the Americas, Vol. I, Ed. Fiocruz, Rio de Janeiro, p. 85-106.

Klug F 1834. In Reise um die Erde, in den Jahren 1830, 1831 und 1832 ausgeführt von FJF Meyen. Teil 1, C W Eichoff, Berlin.

Lent H, Jurberg J 1965. O gênero Psammolestes Bergroth, 1911, com um estudo sôbre a genitália das espécies (Hemiptera, Reduviidae, Triatominae). Rev Brasil Biol 25: 349-376.

Lent H, Wygodzinsky P 1979. Revision of the Triatominae (Hemiptera, Reduviidae) and their significance as vectors of Chagas' disease. Bull Am Mus Nat Hist 163: 123-520.

Lent H, Jurberg J, Galvão C 1993. Rhodnius stali n. sp. afim de Rhodnius pictipes Stal, 1872 (Hemiptera, Reduviidae, Triatominae). Mem Inst Oswaldo Cruz 88: 605-614.

Lent H, Jurberg J, Galvão C 1994. Revalidação do gênero Mepraia Mazza, Gajardo \& Jorg, 1940 (Hemiptera, Reduviidae, Triatominae). Mem Inst Oswaldo Cruz 89: 347-352.

Mejia JM, Galvão C, Jurberg J 1999. Rhodnius colombiensis sp. $\mathrm{n}$. da Colômbia, com quadros comparativos entre estruturas fálicas do gênero Rhodnius Stal, 1859 (Hemiptera, Reduviidae, Triatominae). Entomol Vect 6: 601-617.

Ryckman RE 1962. Biosystematics and hosts of the Triatoma complex in North America. Univ California Publ Ent 27: 93-239.

Usinger RL, Wygodzinsky P, Ryckman RE 1966. The biosystematics of Triatominae. Ann Rev Ent 11: 309330. 